
3
Research Square
Preprints are preliminary reports that have not undergone peer review.
They should not be considered conclusive, used to inform clinical practice, or referenced by the media as validated information.

\title{
The effect of early social contact on the community structure and functions of fecal microbiome in suckling - growing piglets
}

\section{Yanju Bi}

NEAU: Northeast Agricultural University

Runze Liu

NEAU: Northeast Agricultural University

Wenbo Ji

NEAU: Northeast Agricultural University

Lei Pan

NEAU: Northeast Agricultural University

\section{Haidong Wei}

NEAU: Northeast Agricultural University

Jianhong Li

NEAU: Northeast Agricultural University

Xiang Li

NEAU: Northeast Agricultural University

\section{Runxiang Zhang}

NEAU: Northeast Agricultural University

Honggui Liu

NEAU: Northeast Agricultural University

Jun Bao ( $\square$ jbao@neau.edu.cn )

NEAU: Northeast Agricultural University https://orcid.org/0000-0002-9492-0507

\section{Research}

Keywords: Fecal microbiota, Functional pathway, Microbial community structure, Piglets, Social environment

Posted Date: September 21st, 2020

DOI: https://doi.org/10.21203/rs.3.rs-79407/v1

License: (a) (i) This work is licensed under a Creative Commons Attribution 4.0 International License. Read Full License 


\section{Abstract}

Background: Social contact in the early suckling period as an enriched social environment can reduce the aggressive behaviors of piglets at weaning regrouping, and improve their production performance and welfare. We speculated that the social environment could modulate the maturation of piglet intestinal microbiota at later growth stages. Therefore, we performed microbial 16S rRNA gene sequencing from fecal samples, collected at $16,35,42$, and 63 days of age, to investigate the structure and function of intestinal microbiota in piglets that experienced early social contact.

Results: The results showed that the litter weight of the piglets was not significantly different between the control (CON) and social contact (SC) groups at 35 days of age $(P>0.05)$, but the weight of piglets in the SC group significantly decreased at 63 days compared to the CON group $(P<0.05)$. While the proportion of Firmicutes were the most abundant bacterial phylum detected in both groups at all times, the proportion of Firmicutes and the Firmicutes-to-Bacteroides ratio were significantly higher in the SC group compared to the $\mathrm{CON}$ group and the proportion of Bacteroides was lower in the SC group compared to the CON group at 35,42 , and 63 days of age $(P<0.05)$. At the genus level, early social contact had a significant positive effect on the level of Lactobacillus at 35 and 42 days of age $(P<0.05)$, but a negative effect on Prevotella at 35, 42, and 63 days of age $(P<0.05)$. Furthermore, functional analysis of the microbial composition showed that the changes induced by early social contact mainly altered the relative abundance of metabolic and related pathways. From 35 days of age, the social contact notably had a negative effect on the abundance microbial pathways for protein digestion and absorption and lipid metabolism $(P<0.05)$.

Conclusions: Early social contact truly changed the taxonomy of fecal microbiota in piglets, which in turn, impacted the potential for microbial function within the piglet intestine. At present, we speculate that providing continuous social contact negatively influences the nutrient metabolism for the growing piglets.

\section{Background}

The gut microbiota plays a crucial role in the health and disease of the host, providing many functions such as participating in host metabolism and immunity [1]. Colonization of the gut microbiome is a complex process that is mainly affected by age, heredity, diet, and environmental exposures [2]. Many studies in humans [3], mice [4], beat cattle [5], pigs [6], and chickens [7] have shown that different genetic backgrounds can transform the composition of the microbiota. Meanwhile, the fiber, carbohydrate, and protein content in the diet can alter the microbiota in the gut $[8,9]$. Environmental exposures, including latitude [10], temperature [11], social environment [12], among others, are also important for colonization with individual bacterium. The formation and maintenance of a healthy gut microbiome in early life are especially crucial for pigs since the early bacterial population can alter the permanent microbial community structure and function, which, in turn, affect health and growth performance in later life [13]. 
Weaning transition is an important development stage in pigs as it impacts the intestinal microbial structure and function $[14,15]$. Under modern intensive farming practices, farmers pursue economic benefits by weaning piglets at a very early age, which obviously causes stress that depresses piglet food intake, growth, immune response, oxidative stress and neuroendocrine function [16-18]. This stress can even cause diarrhea [18]. In addition, weaning stress will shift the diversity and taxa of intestinal bacteria and, subsequently, the permeability of the intestinal wall, causing functional changes in the gut $[19,20]$. In recent years, intense research efforts have studied the shifts in microbial composition during sucklinggrowing period, proving that the intestinal microbial structure of piglets is unstable and the gut function is affected $[13,14,21]$. Indeed, weaning was found to easily activate inflammation signaling pathways and contribute to abnormal expression of genes and proteins in the host [14,20]. Dietary changes during weaning have been found to influence the absorption of gastroenteric nutrients and the feed efficiency $[14,19]$. In order to lessen the damage caused by weaning, researchers have tried to develop methods to relieve the intensity of weaning stress, such as providing dietary fiber, proteins, minerals, probiotics, and antibiotics [13]. Undoubtedly, these methods alleviated the negative effects of weaning stress, however, consumers are wary of the safety implication of antibiotic residues in meat products. These safety concerns have led some countries, such as the European Union and the USA, to ban the use of antibiotics in farm animal feed.

It has been reported that the early life conditions can influence the health of animals for a long time, for example, early mother-child separation impairs the learning and social ability in calves [22] and rats [23]. However, wild male banded mongooses (Mungos mungo) with poor early life experience have greater lifetime fitness and live longer [24]. Su et al. (2018) showed that the prior cold stimulus in early life could improve the immunity provided by the ileum in broiler chickens [25]. For pigs, it has been reported that the social contact before weaning can increase play behavior and result in a smaller growth reduction after weaning [26]. These differences in early-life environment can make major differences in mucosa-adherent microbial diversity in the ileum of adult pigs [27]. While social contact is a mechanism that can clearly mediate the acquisition and exchange of microbial symbionts [28], the effect of this on the flora colonization remains unclear. Thus, we hypothesized that the social environment can alleviate weaning stress on piglets by improving the intestinal microbial composition and function, which may ultimately benefit health and improve growth.

\section{Methods}

\section{Animals, housing, experimental design, and sampling}

A total of 18 litters of crossbred piglets (Large White $\times$ Duroc $\times$ Min-pig) were selected from those at the Northeast Agricultural University experimental farm in Harbin, China. In our experiment, the weaning age was 35 days, and the growing period was from 36 to 63 days of age. Sows were moved into the farrowing pens 1-week before parturition. The pen size was $2.20 \mathrm{~m} \times 3.00 \mathrm{~m}$ with an area of $0.80 \mathrm{~m} \times$ $1.60 \mathrm{~m}$ for piglet running. The 18-litter piglets were divided into two groups: control (CON) and social contact (SC). The CON group consisted of 6-litter piglets that were not allowed contact with the piglets 
from other litters. At 36 days, these 6 -litter piglets were regrouped into six weaning groups with each group having 10 piglets balanced for body weight and sex. The SC group consisted of the other 12 -litter piglets, where groups of 2 litters (sows) had a shared mutual running area of $2.24 \mathrm{~m}^{2}$ between their adjacent pens. At 36 days of age, the regrouping procedure was the same as the CON group, where 60 piglets selected from the 12 litters were regrouped into six weaning groups, with each group having 10 piglets balanced for body weight and sex. The pens of both groups were fan-ventilated with a controller regulating fan speed thought the experimental process. The temperatures of the suckling and growing periods were $22 \pm 2{ }^{\circ} \mathrm{C}$ and $25 \pm 2{ }^{\circ} \mathrm{C}$ respectively. The piglets were provided with creep feed from 20 to 26 days of age, followed by a 1:1 mix of creep feed and nursery diet starting from 27 days to 33 days of age, after which they were fed the nursery diet from 34 to 63 days of age. The piglets had free access to water and food. The litters of piglets were weighed at 35 and 63 days of age. Fresh feces were collected with sterile cotton at $16,35,42$, and 63 days of age, immediately flash-frozen in liquid nitrogen and stored at $-80^{\circ} \mathrm{C}$ until analyzed.

\section{DNA Extraction, 16S RNA Gene Amplification, and Sequencing}

Total genomic DNA of the feces $(100 \mathrm{mg})$ from each piglet was extracted by the E.Z.N.A. ${ }^{\circledR}$ Stool DNA Kit (D4015, Omega, Inc., USA), following the manufacturer's instructions. The effective total DNA was eluted in $50 \mu \mathrm{L}$ of elution buffer and stored at $-80^{\circ} \mathrm{C}$ until use in polymerase chain reaction (PCR). The V3-V4 region of the $16 \mathrm{~S}$ rRNA gene was amplified by PCR with the barcode fusion forward primer $341 \mathrm{~F}$ (CCTACGGGNGGCWGCAG) and reverse primer 805R (GACTACHVGGGTATCTAATCC), in a $25 \mu \mathrm{L}$ reaction mixture, which contained $12.5 \mu \mathrm{L}$ PCR Premix, $2.5 \mu \mathrm{L}$ forward primer, $2.5 \mu \mathrm{L}$ reverse primer, $25 \mathrm{ng}$ template DNA, and adjusted to the final volume with PCR-grade water. The PCR conditions to amplify the prokaryotic $16 \mathrm{~S}$ fragments consisted of an initial denaturation at $98^{\circ} \mathrm{C}$ for 30 seconds; 32 cycles of denaturation at $98^{\circ} \mathrm{C}$ for 10 seconds, annealing at $54^{\circ} \mathrm{C}$ for 30 seconds, and extension at $72{ }^{\circ} \mathrm{C}$ for 45 seconds; with a final extension at $72{ }^{\circ} \mathrm{C}$ for 10 minutes. PCR products were confirmed by $2 \%$ agarose gel electrophoresis, prior to being further purified with AMPure XT beads (Beckman Coulter Genomics, Danvers, MA, USA) and quantified with a Qubit (Invitrogen, USA). The amplicon pools were prepared for sequencing and the size and quantity of the amplicon library were assessed on an Agilent 2100 Bioanalyzer (Agilent, USA) and with the Library Quantification Kit for Illumina (Kapa Biosciences, Woburn, MA, USA), respectively. The libraries were sequenced on the NovaSeq PE250 platform.

\section{$16 \mathrm{~S}$ rRNA gene sequence bioinformatic analysis}

The 16S rRNA gene sequences were analyzed on an Illumina NovaSeq platform according to the recommendatory manufacturer's instructions provided by LC-Bio. Paired-end reads were assigned to samples based on their unique barcode and truncated by removing the barcode and primer sequences, prior to being merged using FLASH. According to fqtrim (version 0.94), quality filtering of raw read data was performed in order to obtain high-quality clean tags under the specific filtering conditions.

Chimeric sequences were filtered by Vsearch software (version 2.3.4). After dereplication using DADA2, the feature table and sequence was determined. Alpha diversity and beta diversity were randomly 
calculated by being normalized to the same sequences. According to the SILVA (release 132) classifier, the feature abundance was normalized to the relative abundance of each sample. Alpha diversity was applied in analyzing the complexity of species diversity through the use of 4 indices: Chao1, observed species, Shannon, and Simpson, as calculated by Quantitative Insights Into Microbial Ecology 2 (QIME2). Principal coordinate analysis (PCoA) was calculated by QIME2 and plotted by the R package (v3.5.2). Phylogenetic Investigation of Communities by Reconstruction of Unobserved States (PICRUSt, https://picrust.github.io/picrust/) was used to conduct the functional annotation of microbial communities. The software package STAMP was employed to detect the differentially abundant Kyoto Encyclopedia of Genes and Genomes (KEGG) pathways in both groups with false discovery rate correction. The remaining diagrams were plotted with the $\mathrm{R}$ package ( $\mathrm{v} 3.5 .2)$.

The differences in alpha diversity (Chao1, observed species, Shannon, and Simpson indices), the Firmicutes/Bacteroidetes ratio, and litter weight between the 2 groups were analyzed by the Wilcoxon rank-sum test with False discovery rate (FDR) correction, and the relative abundance of Clusters of Orthologous Groups (COGs) and KEGG pathways were compared by the t-test. All indices were presented as the mean \pm standard deviation (SD). The value of $P<0.05$ was considered statistically significant.

\section{Results}

\section{Sequencing data for all samples}

To investigate the influence of the early social contact on the gut microbiota of piglets, fresh fecal samples from the CON and SC groups were collected at 16, 35, 42, and 63 days of age. A total of 10,335,418 high-qualified sequences from 151 samples were obtained, and the results of per sample are displayed in Additional file 1: Table S1. The rarefaction curves for each sample are displayed in Fig. 1 and implied that almost all of the bacterial species identified were captured in all samples. The obtained sequences were randomly analyzed.

\section{Alpha And Beta Diversity Analysis}

The alpha diversity indices (Chao1, observed species, Shannon, and Simpson) are shown in Table 1. The richness of the microbiota in the feces from the SC group was significantly lower than that in the CON group at the age of 16 and 35 days, as measured by the Chao1 and observed species indices $(P<0.001)$, while no significant difference was observed in the CON and SC groups at 42 and 63 days $(P>0.05)$. When compared to the CON group, the Shannon index in the SC group was significantly lower at 16 days of age $(P=0.018)$, but showed no significant difference at 35,42 , and 63 days of age $(P>0.05)$. However, the Simpson index was significantly decreased in SC group at 16,42 , and 63 days compared with the CON group $(P<0.05)$, but showed no difference at 35 days of age $(P>0.05)$. Based on Bray-Curtis distance and weighted Unifrac distances, the PCoA plot justified that the microbiota of CON and SC groups were relatively separated at any of the sampled time-points $(P<0.001)$ (Fig. 2). 
Table 1

Effects of social contact on alpha diversity of fecal microbiota in piglets

\begin{tabular}{|c|c|c|c|c|c|c|}
\hline Items & & n & Chao1 & Observed species & Shannon & Simpson \\
\hline \multirow[t]{3}{*}{$16 \mathrm{~d}$} & CON & 20 & $415.75 \pm 119.88$ & $380.50 \pm 103.24$ & $5.96 \pm 0.84$ & $0.95 \pm 0.05$ \\
\hline & SC & 20 & $263.71 \pm 101.79$ & $253.50 \pm 96.37$ & $5.60 \pm 0.65$ & $0.94 \pm 0.03$ \\
\hline & $P$-value & - & $2.9 \mathrm{e}-0.5^{\star \star \star}$ & $<0.001^{\star \star \star}$ & $0.018^{*}$ & $0.035^{*}$ \\
\hline \multirow[t]{3}{*}{$35 d$} & CON & 20 & $728.28 \pm 229.27$ & $657.45 \pm 196.97$ & $6.70 \pm 1.01$ & $0.96 \pm 0.05$ \\
\hline & SC & 20 & $479.89 \pm 222.43$ & $453.55 \pm 191.28$ & $6.69 \pm 0.96$ & $0.97 \pm 0.03$ \\
\hline & $P$-value & - & $0.002^{\star \star}$ & $0.004^{\star \star}$ & 0.990 & 0.600 \\
\hline \multirow[t]{3}{*}{$42 \mathrm{~d}$} & CON & 20 & $481.76 \pm 141.73$ & $449.55 \pm 124.44$ & $7.39 \pm 0.46$ & $0.99 \pm 0.004$ \\
\hline & SC & 15 & $426.87 \pm 120.52$ & $401.60 \pm 109.48$ & $6.81 \pm 0.70$ & $0.97 \pm 0.03$ \\
\hline & $P$-value & - & 0.180 & 0.370 & 0.180 & $0.012^{*}$ \\
\hline \multirow[t]{3}{*}{$63 d$} & CON & 20 & $452.38 \pm 102.45$ & $438.55 \pm 96.89$ & $7.32 \pm 0.42$ & $0.98 \pm 0.01$ \\
\hline & SC & 16 & $487.41 \pm 144.66$ & $467.75 \pm 131.38$ & $7.12 \pm 0.57$ & $0.97 \pm 0.02$ \\
\hline & $P$-value & - & 0.300 & 0.390 & 0.320 & $0.023^{*}$ \\
\hline
\end{tabular}

\section{Microbial Composition}

The composition of fecal microflora of piglets at the age of 16, 35, 42 and 63 days is shown in Fig. 3. At the phylum level (Fig. 3A), Firmicutes and Bacteroidetes were the dominant phyla in the feces at all timepoints, with an abundance of over $80 \%$ of the population and even more than $90 \%$ after weaning. The abundance of Firmicutes in both groups increased with age except at 42 days of age. The abundance of Firmicutes and Bacteroidetes in the SC group showed no significant difference compared with the CON group at 16 days of age $(P>0.05)$. However, the abundance of Firmicutes in the SC group was notably higher than that in the CON group at 35,42 and 63 days of age $(P<0.05)$, while the abundance of Bacteroidetes in the SC group was notably lower than that in the CON group at 35, 42 and 63 days of age $(P<0.05)$. The remaining bacteria identified were Actinobacteria, Proteobacteria, Spirochaetes, and Fusobacteria. The abundance of Actinobacteria in the SC group was significantly higher than that in the CON group at 16,35 , and 63 days of age $(P<0.05)$, as was the proportion of Proteobacteria at 63 days of age $(P<0.05)$. However, the proportion of Proteobacteria was notably lower in SC pigs at 16 and 35 days of age $(P>0.05)$. Finally, the abundance of Fusobacteria in the SC group was significantly decreased at 
35 days of age compared with that of the CON group $(P<0.05)$. In general, the phylum-level analysis determined that the group exposed to a social environmental had an increase in the proportion of Firmicutes and Actinobacteria and a decrease in the proportion of Bacteroidetes. Besides, the Firmicutesto Bacteroidetes ratio in the SC group was significantly higher than that in the CON group at the age of $35,42$, and 63 days $(P<0.05)$, but was not significantly different at 16 days of age $(P>0.05)$ (Fig. 4$)$.

At the family level (Fig. 3B), Ruminococcaceae formed the largest proportion of the microbiome at all detection times in both groups. However, Muribaculaceae was the second-largest proportion of bacteria during the suckling period ( 16 and 35 days of age) in both groups but decreased after weaning (42 and 63 days of age). Meanwhile, Lactobacillaceae and Lachnospiraceae were increased after weaning in both groups, to become the second and third largest proportion of the population, respectively. The proportion of Prevotellaceae in the SC group was significantly decreased than for the CON group at 35, 42, and 63 days of age $(P<0.05)$, while the proportion of Bacteroidaceae in the SC group was less than that in the CON group at the age of 16,35 , and 63 days $(P<0.05)$, but increased significantly at 42 days of age $(P<$ 0.05).

At the genus level (Fig. 3C), Muribaculacesae was the most prevalent genus during the suckling period in both groups, while Lactobacillus and Muribaculacesae were the most prevalent genera during the growing period. Meanwhile, the relative abundance of Bacteroides was enriched at the suckling period, but gradually decreased with the age. Conversely, the proportion of Ruminococcaceae_UCG-014, Faecalibacterium and Subdoligranulum were very low during the suckling period, but they continuously increased with the age. In addition, Fig. 5 (A, B, C, and D) showed that the proportion of Lactobacillus in the SC group was significantly increased compared with the CON group at all time-points $(P<0.05)$, while the abundance of Prevotella in the SC group was significantly decreased over that of the CON group $(P<$ 0.05). Other genera fluctuated, but the proportions of Eubacterium-coprostanoligenes_group, Ruminococcaceae_UCG-002, and Ruminococcaceae_UCG-005 in the SC group were markedly increased compared with the CON group at 63 days $(P<0.05)$ while the abundance of Alloprevotella significantly decreased in the SC group $(P<0.05)$.

\section{Functional changes in the fecal microbiota induced by social contact}

PICRUSt was applied in this study to investigate the functional and metabolic potentials of the pig fecal microbiota and the possible changes induced by social contact based on the next-generation sequencing reads. According to the results, the most abundant COG families in the feces at 16 and 35 days of age were response regulators including Signal transduction histidine kinase (COG\#0642), Site-specific recombinase XerD (COG\#4974), Response regulators consisting of a CheY-like receiver domain and a winged-helix DNA-binding domain (COG\#0745), AraC-type DNA-binding domain-containing proteins (COG\#2207), and Na+-driven multidrug efflux pump (COG\#0534) (Additional file 2: Table S2 and Additional file 3: Table S3). At 35 and 42 days of age, the most abundant COG families were response regulators including Signal transduction histidine kinase (COG\#0642), Site-specific recombinase XerD (COG\#4974), Response regulators consisting of a CheY-like receiver domain and a winged-helix DNA- 
binding domain (COG\#0745), ABC-type multidrug transport system, ATPase and permease components (COG\#1132), and Na+-driven multidrug efflux pump (COG\#0534) (Additional file 4: Table S4 and Additional file 5: Table S5). Pre- and post-weaning, there was one change in the composition of the COG families. At these time-points, the most abundant COG functional categories (classes) were Signal transduction mechanisms (category T), Defense mechanisms (category V), Transcription (category K), and Replication, recombination, and repair (category $L$ ). The social contact had a significant effect on the functional categories of the microbiota in the feces, as shown in Tables 2-5. For example, the abundance of Post-translational modification, protein turnover, and chaperones (category 0 ), carbohydrate transport and metabolism (category $\mathrm{G}$ ), and coenzyme transport and metabolism (category $\mathrm{H}$ ) in the SC group were notably different from the CON group $(P<0.05)$. Categories 0 and $\mathrm{H}$ significantly increased at 16 days of age for $\mathrm{SC}$ compared with the CON group $(P<0.05)$, but were significantly decreased at 35,42 , and 63 days of age $(P<0.05)$. Conversely, the $\mathrm{G}$ category in the SC group significantly decreased at 16 days of age compared to the CON group $(P<0.05)$, but significantly increased at 35,42 , and 63 days of age $(P<0.05)$. The social contact implied to have significant effects on some functional categories of microbiota in the feces. Especially in cellular processes and signaling, Functional categories for: the abundance of Cell wall/membrane/envelope biogenesis (category M), Post-translational modification, protein turnover, and chaperones (category 0 ) and Intracellular trafficking, secretion, and vesicular transport (category $\mathrm{U}$ ) were notably lower in the SC group than in the CON group at 35, 42 and 63 days of age $(P<0.05)$. Additionally, for metabolism categories, when compared to the CON group, the abundance of Coenzyme transport and metabolism (category $\mathrm{H}$ ) and Lipid transport and metabolism (category I) were significantly lower in the SC group at 35, 42 and 63 days of age $(P<0.05)$, while the abundance of Carbohydrate transport and metabolism (G category) was significantly higher $(P<0.05)$, as was the abundance of Amino acid transport and metabolism (category E) in the SC group at 35 and 42 days of age $(P<0.05)$. 
Table 2

COG function of classes identified in feces of piglets at 16 days of age

\begin{tabular}{|c|c|c|c|c|}
\hline COG_class & Description & CON & SC & $P$-value \\
\hline D & $\begin{array}{l}\text { Cell cycle control, cell division, chromosome } \\
\text { partitioning }\end{array}$ & $\begin{array}{l}1.24 \pm \\
0.10\end{array}$ & $\begin{array}{l}1.38 \pm \\
0.03\end{array}$ & $\begin{array}{l}< \\
0.001^{* \star \star}\end{array}$ \\
\hline 0 & $\begin{array}{l}\text { Post-translational modification, protein turnover, } \\
\text { and chaperones }\end{array}$ & $\begin{array}{l}2.96 \pm \\
0.13\end{array}$ & $\begin{array}{l}3.17 \pm \\
0.17\end{array}$ & $\begin{array}{l}< \\
0.001^{* \star *}\end{array}$ \\
\hline $\mathrm{T}$ & Signal transduction mechanisms & $\begin{array}{l}5.51 \pm \\
0.34\end{array}$ & $\begin{array}{l}4.78 \pm \\
0.41\end{array}$ & $\begin{array}{l}< \\
0.001^{* \star \star}\end{array}$ \\
\hline V & Defense mechanisms & $\begin{array}{l}2.73 \pm \\
0.18\end{array}$ & $\begin{array}{l}2.86 \pm \\
0.16\end{array}$ & $0.021^{*}$ \\
\hline A & RNA processing and modification & $\begin{array}{l}0.00 \pm \\
0.01\end{array}$ & $\begin{array}{l}0.00 \pm \\
0.01\end{array}$ & $0.020^{\star}$ \\
\hline J & Translation, ribosomal structure and biogenesis & $\begin{array}{l}6.19 \pm \\
0.49\end{array}$ & $\begin{array}{l}7.26 \pm \\
0.22\end{array}$ & $\begin{array}{l}< \\
0.001^{* \star \star}\end{array}$ \\
\hline K & Transcription & $\begin{array}{l}8.51 \pm \\
0.54\end{array}$ & $\begin{array}{l}8.06 \pm \\
0.53\end{array}$ & $0.012^{*}$ \\
\hline L & Replication, recombination and repair & $\begin{array}{l}6.44 \pm \\
0.40\end{array}$ & $\begin{array}{l}7.25 \pm \\
0.18\end{array}$ & $\begin{array}{l}< \\
0.001^{* \star \star}\end{array}$ \\
\hline $\mathrm{F}$ & Nucleotide transport and metabolism & $\begin{array}{l}2.94 \pm \\
0.19\end{array}$ & $\begin{array}{l}3.23 \pm \\
0.12\end{array}$ & $\begin{array}{l}< \\
0.001^{* * \star}\end{array}$ \\
\hline G & Carbohydrate transport and metabolism & $\begin{array}{l}9.64 \pm \\
0.66\end{array}$ & $\begin{array}{l}8.32 \pm \\
0.55\end{array}$ & $\begin{array}{l}< \\
0.001^{* \star \star}\end{array}$ \\
\hline $\mathrm{H}$ & Coenzyme transport and metabolism & $\begin{array}{l}4.05 \pm \\
0.24\end{array}$ & $\begin{array}{l}4.25 \pm \\
0.32\end{array}$ & $0.032^{*}$ \\
\hline$P$ & Inorganic ion transport and metabolism & $\begin{array}{l}4.81 \pm \\
0.32\end{array}$ & $\begin{array}{l}4.50 \pm \\
0.18\end{array}$ & $0.001^{\star \star \star}$ \\
\hline$Q$ & $\begin{array}{l}\text { Secondary metabolites biosynthesis, transport, } \\
\text { and catabolism }\end{array}$ & $\begin{array}{l}1.10 \pm \\
0.11\end{array}$ & $\begin{array}{l}1.03 \pm \\
0.08\end{array}$ & $0.013^{*}$ \\
\hline $\mathrm{R}$ & General function prediction only & $\begin{array}{l}11.64 \pm \\
0.33\end{array}$ & $\begin{array}{l}11.47 \pm \\
0.15\end{array}$ & $0.048^{\star}$ \\
\hline \multicolumn{5}{|c|}{$\begin{array}{l}\text { Note. The data are presented as means } \pm \text { SD. CON, control group; SC, social contact. No superscript } \\
\text { represents no significant difference }(P>0.05),{ }^{*, * *} \text {, and }{ }^{* \star *} \text { represent } P<0.05, P<0.01 \text {, and } P<0.001 \text {, } \\
\text { respectively. }\end{array}$} \\
\hline
\end{tabular}


Table 3

COG function of classes identified in feces of piglets at 35 days of age

\begin{tabular}{|c|c|c|c|c|}
\hline COG_class & Description & CON & SC & $P$-value \\
\hline M & Cell wall/membrane/envelope biogenesis & $\begin{array}{l}6.89 \pm \\
0.54\end{array}$ & $\begin{array}{l}6.31 \pm \\
0.55\end{array}$ & $0.002^{\star \star}$ \\
\hline 0 & $\begin{array}{l}\text { Post-translational modification, protein turnover, and } \\
\text { chaperones }\end{array}$ & $\begin{array}{l}3.14 \pm \\
0.17\end{array}$ & $\begin{array}{l}2.97 \pm \\
0.12\end{array}$ & $0.001^{* *}$ \\
\hline U & $\begin{array}{l}\text { Intracellular trafficking, secretion, and vesicular } \\
\text { transport }\end{array}$ & $\begin{array}{l}1.94 \pm \\
0.16\end{array}$ & $\begin{array}{l}1.67 \pm \\
0.20\end{array}$ & $\begin{array}{l}< \\
0.001^{* * *}\end{array}$ \\
\hline V & Defense mechanisms & $\begin{array}{l}2.78 \pm \\
0.13\end{array}$ & $\begin{array}{l}2.99 \pm \\
0.08\end{array}$ & $\begin{array}{l}< \\
0.001^{* * *}\end{array}$ \\
\hline W & Extracellular structures & $\begin{array}{l}0.00 \pm \\
0.00\end{array}$ & $\begin{array}{l}0.00 \pm \\
0.00\end{array}$ & $0.011^{*}$ \\
\hline A & RNA processing and modification & $\begin{array}{l}0.00 \pm \\
0.00\end{array}$ & $\begin{array}{l}0.00 \pm \\
0.00\end{array}$ & $\begin{array}{l}< \\
0.001^{* * *}\end{array}$ \\
\hline K & Transcription & $\begin{array}{l}8.23 \pm \\
0.58\end{array}$ & $\begin{array}{l}8.88 \pm \\
0.41\end{array}$ & $\begin{array}{l}< \\
0.001^{\star \star *}\end{array}$ \\
\hline L & Replication, recombination and repair & $\begin{array}{l}7.05 \pm \\
0.23\end{array}$ & $\begin{array}{l}7.24 \pm \\
0.19\end{array}$ & $0.008^{\star \star}$ \\
\hline C & Energy production and conversion & $\begin{array}{l}5.50 \pm \\
0.23\end{array}$ & $\begin{array}{l}5.31 \pm \\
0.17\end{array}$ & $0.007^{\star *}$ \\
\hline G & Carbohydrate transport and metabolism & $\begin{array}{l}8.36 \pm \\
0.46\end{array}$ & $\begin{array}{l}8.67 \pm \\
0.25\end{array}$ & $0.014^{*}$ \\
\hline $\mathrm{H}$ & Coenzyme transport and metabolism & $\begin{array}{l}4.19 \pm \\
0.25\end{array}$ & $\begin{array}{l}4.00 \pm \\
0.15\end{array}$ & $0.007^{\star *}$ \\
\hline I & Lipid transport and metabolism & $\begin{array}{l}2.45 \pm \\
0.07\end{array}$ & $\begin{array}{l}2.32 \pm \\
0.09\end{array}$ & $\begin{array}{l}< \\
0.001^{\star \star \star}\end{array}$ \\
\hline$P$ & Inorganic ion transport and metabolism & $\begin{array}{l}4.58 \pm \\
0.23\end{array}$ & $\begin{array}{l}4.32 \pm \\
0.09\end{array}$ & $\begin{array}{l}< \\
0.001^{* \star *}\end{array}$ \\
\hline Q & $\begin{array}{l}\text { Secondary metabolites biosynthesis, transport, and } \\
\text { catabolism }\end{array}$ & $\begin{array}{l}1.08 \pm \\
0.07\end{array}$ & $\begin{array}{l}0.99 \pm \\
0.05\end{array}$ & $<.001^{\star \star \star}$ \\
\hline \multicolumn{5}{|c|}{$\begin{array}{l}\text { Note. The data are presented as means } \pm \text { SD. CON, control group; SC, social contact group. No } \\
\text { superscript represents no significant difference }(P>0.05),{ }^{* * *}, \text { and }{ }^{* \star} \text { represent } P<0.05, P<0.01 \text {, and } P \\
<0.001 \text {, respectively. }\end{array}$} \\
\hline
\end{tabular}


Table 4

COG function of classes identified in feces of piglets at 42 days of age

\begin{tabular}{|c|c|c|c|c|}
\hline COG_class & Description & CON & sc & $P$-value \\
\hline M & Cell wall/membrane/envelope biogenesis & $\begin{array}{l}6.41 \pm \\
0.24\end{array}$ & $\begin{array}{l}6.07 \pm \\
0.22\end{array}$ & $\begin{array}{l}< \\
0.001^{\star \star \star}\end{array}$ \\
\hline $\mathrm{N}$ & Cell motility & $\begin{array}{l}1.22 \pm \\
0.27\end{array}$ & $\begin{array}{l}0.95 \pm \\
0.21\end{array}$ & $0.002^{* *}$ \\
\hline 0 & $\begin{array}{l}\text { Post-translational modification, protein turnover, } \\
\text { and chaperones }\end{array}$ & $\begin{array}{l}3.04 \pm \\
0.87\end{array}$ & $\begin{array}{l}2.91 \pm \\
0.06\end{array}$ & $\begin{array}{l}< \\
0.001^{\star \star \star}\end{array}$ \\
\hline $\mathrm{T}$ & Signal transduction mechanisms & $\begin{array}{l}5.44 \pm \\
0.30\end{array}$ & $\begin{array}{l}5.20 \pm \\
0.29\end{array}$ & $0.021^{*}$ \\
\hline U & $\begin{array}{l}\text { Intracellular trafficking, secretion, and vesicular } \\
\text { transport }\end{array}$ & $\begin{array}{l}1.73 \pm \\
0.10\end{array}$ & $\begin{array}{l}1.56 \pm \\
0.13\end{array}$ & $\begin{array}{l}< \\
0.001^{* \star *}\end{array}$ \\
\hline V & Defense mechanisms & $\begin{array}{l}3.03 \pm \\
0.07\end{array}$ & $\begin{array}{l}2.95 \pm \\
0.08\end{array}$ & $0.008^{* \star}$ \\
\hline W & Extracellular structures & $\begin{array}{l}0.00 \pm \\
0.00\end{array}$ & $\begin{array}{l}0.00 \pm \\
0.00\end{array}$ & $0.023^{*}$ \\
\hline Z & Cytoskeleton & $\begin{array}{l}0.01 \pm \\
0.00\end{array}$ & $\begin{array}{l}0.01 \pm \\
0.00\end{array}$ & $\begin{array}{l}< \\
0.001^{\star \star \star}\end{array}$ \\
\hline B & Chromatin structure and dynamics & $\begin{array}{l}0.01 \pm \\
0.00\end{array}$ & $\begin{array}{l}0.02 \pm \\
0.00\end{array}$ & $0.004^{\star \star}$ \\
\hline L & Replication, recombination and repair & $\begin{array}{l}7.30 \pm \\
0.20\end{array}$ & $\begin{array}{l}7.56 \pm \\
0.36\end{array}$ & $0.019^{\star}$ \\
\hline E & Amino acid transport and metabolism & $\begin{array}{l}7.75 \pm \\
0.16\end{array}$ & $\begin{array}{l}7.99 \pm \\
0.13\end{array}$ & $\begin{array}{l}< \\
0.001^{\star \star \star}\end{array}$ \\
\hline $\mathrm{F}$ & Nucleotide transport and metabolism & $\begin{array}{l}3.09 \pm \\
0.09\end{array}$ & $\begin{array}{l}3.26 \pm \\
0.20\end{array}$ & $0.006^{* *}$ \\
\hline G & Carbohydrate transport and metabolism & $\begin{array}{l}8.78 \pm \\
0.32\end{array}$ & $\begin{array}{l}9.04 \pm \\
0.25\end{array}$ & $0.011^{*}$ \\
\hline $\mathrm{H}$ & Coenzyme transport and metabolism & $\begin{array}{l}4.04 \pm \\
0.08\end{array}$ & $\begin{array}{l}3.84 \pm \\
0.12\end{array}$ & $\begin{array}{l}< \\
0.001^{* \star *}\end{array}$ \\
\hline I & Lipid transport and metabolism & $\begin{array}{l}2.36 \pm \\
0.06\end{array}$ & $\begin{array}{l}2.31 \pm \\
0.05\end{array}$ & $0.014^{\star}$ \\
\hline $\mathrm{R}$ & General function prediction only & $\begin{array}{l}11.38 \pm \\
0.12\end{array}$ & $\begin{array}{l}11.50 \pm \\
0.08\end{array}$ & $0.003^{* \star}$ \\
\hline
\end{tabular}

Note. The data are presented as means \pm SD. CON, control group; SC, social control group. No superscript represents no significant difference $(P>0.05),{ }^{*}{ }^{* *}$, and ${ }^{* * *}$ represent $P<0.05, P<0.01$, and $P$ $<0.001$, respectively. 


\begin{tabular}{|c|c|c|c|c|}
\hline COG_class & Description & CON & SC & $P$-value \\
\hline$S$ & Function unknown & $\begin{array}{l}6.93 \pm \\
0.10\end{array}$ & $\begin{array}{l}7.37 \pm \\
0.34\end{array}$ & $\begin{array}{l}< \\
0.001^{* \star *}\end{array}$ \\
\hline \multicolumn{5}{|c|}{$\begin{array}{l}\text { Note. The data are presented as means } \pm \text { SD. CON, control group; SC, social control group. No } \\
\text { superscript represents no significant difference }(P>0.05),{ }^{* * *}, \text { and }{ }^{* \star *} \text { represent } P<0.05, P<0.01 \text {, and } P \\
<0.001 \text {, respectively. }\end{array}$} \\
\hline
\end{tabular}


Table 5

COG function of classes identified in feces of piglets at 63 days of age

\begin{tabular}{|c|c|c|c|c|}
\hline COG_class & Description & $\operatorname{CON}$ & SC & $P$-value \\
\hline M & Cell wall/membrane/envelope biogenesis & $\begin{array}{l}6.61 \pm \\
0.47\end{array}$ & $\begin{array}{l}6.26 \pm \\
0.18\end{array}$ & $0.005^{\star \star}$ \\
\hline 0 & $\begin{array}{l}\text { Post-translational modification, protein turnover, and } \\
\text { chaperones }\end{array}$ & $\begin{array}{l}3.12 \pm \\
0.15\end{array}$ & $\begin{array}{l}2.98 \pm \\
0.06\end{array}$ & $\begin{array}{l}< \\
0.001^{* \star \star}\end{array}$ \\
\hline U & $\begin{array}{l}\text { Intracellular trafficking, secretion, and vesicular } \\
\text { transport }\end{array}$ & $\begin{array}{l}1.73 \pm \\
0.09\end{array}$ & $\begin{array}{l}1.66 \pm \\
0.10\end{array}$ & $0.033^{*}$ \\
\hline Z & Cytoskeleton & $\begin{array}{l}0.01 \pm \\
0.00\end{array}$ & $\begin{array}{l}0.01 \pm \\
0.00\end{array}$ & $0.032^{*}$ \\
\hline B & Chromatin structure and dynamics & $\begin{array}{l}0.01 \pm \\
0.00\end{array}$ & $\begin{array}{l}0.02 \pm \\
0.00\end{array}$ & $0.006^{* *}$ \\
\hline K & Transcription & $\begin{array}{l}8.58 \pm \\
0.45\end{array}$ & $\begin{array}{l}8.83 \pm \\
0.19\end{array}$ & $0.034^{*}$ \\
\hline C & Energy production and conversion & $\begin{array}{l}5.20 \pm \\
0.13\end{array}$ & $\begin{array}{l}5.07 \pm \\
0.15\end{array}$ & $0.011^{*}$ \\
\hline E & Amino acid transport and metabolism & $\begin{array}{l}7.75 \pm \\
0.24\end{array}$ & $\begin{array}{l}7.88 \pm \\
0.09\end{array}$ & $0.035^{*}$ \\
\hline G & Carbohydrate transport and metabolism & $\begin{array}{l}8.42 \pm \\
0.30\end{array}$ & $\begin{array}{l}8.83 \pm \\
0.33\end{array}$ & $0.001^{* *}$ \\
\hline $\mathrm{H}$ & Coenzyme transport and metabolism & $\begin{array}{l}4.12 \pm \\
0.17\end{array}$ & $\begin{array}{l}3.85 \pm \\
0.13\end{array}$ & $\begin{array}{l}< \\
0.001^{* \star \star}\end{array}$ \\
\hline I & Lipid transport and metabolism & $\begin{array}{l}2.44 \pm \\
0.11\end{array}$ & $\begin{array}{l}2.37 \pm \\
0.09\end{array}$ & $0.035^{\star}$ \\
\hline$P$ & Inorganic ion transport and metabolism & $\begin{array}{l}4.29 \pm \\
0.14\end{array}$ & $\begin{array}{l}4.15 \pm \\
0.07\end{array}$ & $\begin{array}{l}< \\
0.001^{* * \star}\end{array}$ \\
\hline S & Function unknown & $\begin{array}{l}6.98 \pm \\
0.25\end{array}$ & $\begin{array}{l}7.22 \pm \\
0.26\end{array}$ & $0.007^{\star *}$ \\
\hline \multicolumn{5}{|c|}{$\begin{array}{l}\text { Note. The data are presented as means } \pm \text { SD. CON, control group; SC, social contact group. No } \\
\text { superscript represents no significant difference }(P>0.05),{ }^{* \star *}, \text { and }{ }^{\star \star \star} \\
<0.001 \text {, respectively. }\end{array}$} \\
\hline
\end{tabular}

To predict the probable functional changes induced by the social contact, next-generation sequencing reads were further analyzed to determine the third level of the KEGG pathways. As seen in Fig. 6 , the social contact did not affect the microbial abundance of KEGG pathways at 16 days of age $(P>0.05)$. However, at 35, 42, and 63 days of age, piglets in the SC group had a lower enrichment of KEGG pathways involved in: Arachidonic acid metabolism, Citrate cycle (TCA cycle), Glycan biosynthesis and metabolism, Glycine, serine and threonine metabolism, Nicotinate and nicotinamide metabolism, Oxidative phosphorylation, Phenylalanine metabolism, Protein digestion and absorption, Riboflavin 
metabolism, Vitamin B6 metabolism, Tropane, piperidine, and pyridine alkaloid biosynthesis as well as Steroid hormone biosynthesis. While other pathways including: Galactose metabolism, Glycerolipid metabolism, Glycolysis/Gluconeogenesis, Pentose phosphate pathway, Pyruvate metabolism, Replication, recombination and repair proteins, Transcription factors, and Transporters were higher in the CON group at 35,42 , and 63 days of age.

\section{Weight Of Piglets}

As shown in Fig. 7, there was no significant difference in the weight at the age of 35 days between the CON and SC groups $(P>0.05)$, but a significant decrease was observed in the weight for the SC group compared to the CON group at 63 days of age $(P<0.05)$.

\section{Discussion}

As we all know, the weaning transition has a vital impact on the life of a pig, due mainly to the challenges and stresses of shifting diets, separation from the mother and litter mates, a new social order and new environment, which induce intestinal immune dysfunction that can impact production efficiencies such as growth, food intake, morbidity, and mortality [17]. These stresses can also change microbial diversity and composition.

Garcia et al. (2019) demonstrated that there was no significant change in the microbial richness and diversity in the feces of the piglets at 28 days of age under commercial conditions and early social contact groups. Differences appeared at 31 days of age [29]. The piglets were weaned at the age of 28 days in Garcia's study. However, in our study, where piglets were weaned at 35 days, the presence of a social contact group affected the microbial richness in the feces during the suckling period, but no difference was seen during the growing period. Meanwhile, a difference in the microbial diversity was observed between the treatment groups at the age of 16,42, and 63 days. The deviation between the study results may be attributable to the species of the pig, since three-way crossbred piglets (Large White $\times$ Duroc $\times$ Min-pig) were used in our experiment. The Min-pig is an endemic breed in the northeast China and its genetic factors may influence our results. Interestingly, we found that the early social contact could influence the microbial richness during the suckling period ( 16 and 35 days of age), and seemed to result in a smaller decrease in microbial richness caused by weaning. In addition, beta-diversity showed that the composition of the fecal microbial communities was clearly separated in the treatment groups based on the Bray-Curtis distance weighted Unifrac distances. The early social contact indeed influenced the microbial structure in the piglets.

During the weaning transition, the diet of the piglets was converted from breast milk to plant feed. Many studies have shown that whether before or after weaning, the primary proportion of bacterial phyla were Firmicutes and Bacteroidetes in the feces and large intestine of piglets [14,20,30], consistent with our study, and the next most abundant phyla were Proteobacteria and Actinobacteria. The proportion of Fusobacteria, Verrucomicrobia, and Planctomycetes gradually decreased after weaning in both groups until they were not detectable, indicating that these phyla maybe not adapt to the intestinal environment 
of weaning piglets. Significant influence on several bacteria was provided by early social contact. For instance, the proportion of Firmicutes in the SC group was notably higher than that in the CON group, but Bacteroidetes in the SC group was significantly lower than that in the CON group. Simultaneously the Firmicutes to Bacteroidetes ratio in the SC group was significantly increased compared to the CON group, consistent with previous research [31]. In the human study, the higher Firmicutes-to-Bacteroidetes ratio was observed in obese children compared with the normal-weight children [32], a result also observed in pigs [31]. However, in our study, while the Firmicutes to Bacteroidetes ratio was elevated, the weight of piglets was reduced at 63 days of age in the SC group compared to the CON group, which suggested that the early social contact might lead to these changes. Furthermore, He et al. (2019), also found that primiparous sows had a higher ratio of Firmicutes to Bacteroidetes under heat stress, thought to be due to the fact that the host was in a state of negative energy balance, and that the gut microbiota tended to alter its composition to absorb more energy from the food [11]. Therefore, these results elucidated that the piglets in the social contact group could gain more calories from the nursery diet, and the early social contact might have a negative effect on the energy balance.

On the genus level, it is well documented that Bacteroides are known to provide an advantage in the use of milk oligosaccharides as carbon sources [33]. Similar with other studies, the abundance of Bacteroides was higher before weaning in both groups $[14,15]$. However, the abundance of Bacteroides in the SC group was significantly lower than that in the CON group, which might suggest that the early social contact might help the piglets communicate more and eat more of the solid food that we supplied, as both groups of piglets could freely access solid food from 20 days of age. Generally, it is well known that $10 \%$ of total energy comes from the large intestine of omnivorous animals. The genus Lactobacillus has the ability to consume plant-derived monosaccharide and disaccharide carbohydrates and thus have many genes encoding carbohydrate transport and utilization related capabilities [34]. The genus Prevotella is associated with fermentation of non-starch polysaccharides, extracted from plants into short-chain fatty acids [35] which provide energy for intestinal homeostasis and protect against intestinal inflammation and oxidative stress [36]. Both Lactobacillus and Prevotella play important roles in the utilization of complex carbohydrates, for example Lactobacillus mainly use $\beta$-glucan, gum arabic, and raffinose and stachyose from the diet to ferment chain fatty acids, while Prevotella mainly use hemicelluloses (xylan and arabinoxylan), $\beta$-Glucan, and laminarin to ferment the chain fatty acids [37]. In our study, the early social contact increased the abundance of Lactobacillus but decreased the abundance of Prevotella, which might suggest that this contact influenced the ability of different bacteria to utilize carbohydrate energy sources in the piglets. Otherwise, the abundance of Alloprevotella, that exhibit antiinflammatory function [38], was predominantly lower in the SC group compared to the CON group, consistent with the fact that the gut microbiota plays a vital role in immunity and metabolism [1]. According to the results of functional prediction, the early social contact had an effect on nutrient metabolism of piglets: a negative influence on the metabolism of coenzyme, lipid, and amino acids; but a positive influence on carbohydrate transport and metabolism. Nonetheless, the abundance of defense mechanisms was higher in the SC group before weaning, but lower at 42 days of age, which elucidated that the social contact environment of the suckling pigs might attenuate the weaning stresses. 
Gut microbiota take part in many functional metabolic pathways to influence nutrient digestion and absorption, lipid metabolism and hormone biosynthesis. These can, in turn, affect host behaviors such as social communication, stress response, cognition and feeding behavior [39]. Thus, we further analyzed the functional pathway enrichment to predict the influence of the early social contact on the gut microbial functions of piglets. Our present study showed that the fecal microbiota in the social contact group had no alternation in functions at the beginning (16 days of age). However, from 35 days of age, early social contact had a negative effect on the enrichment of pathways for: Arachidonic acid metabolism, Citrate cycle (TCA cycle), Glycan biosynthesis and metabolism, Nicotinate and nicotinamide metabolism, Oxidative phosphorylation, Protein digestion and absorption, Riboflavin metabolism, Vitamin B6 metabolism, and Tropane, and piperidine and Pyridine alkaloid biosynthesis. Li et al. (2018) demonstrated that Phenylalanine metabolism, Citrate cycle (TCA cycle), Glycolysis or gluconeogenesis, Propanoate metabolism, as well as Nicotinate and nicotinamide metabolism were the key relevant metabolic pathways involved in weaning stress induced gut microbiota dysbiosis, and the abundance of these five metabolic pathways significantly decreased in the weaning pig [20]. These data might show that the early social contact causes the gut microbiota dysbiosis. While the pathway enrichments of Galactose metabolism, Glycerolipid metabolism, Glycolysis/Gluconeogenesis, Pentose phosphate pathway and Pyruvate metabolism transporters in the enriched environment were markedly increased compared to the control group. As described above, it is suggesting that the social contact might decrease the abilities for metabolism of lipids, proteins and energy, but the ability for monosaccharide metabolism and absorption was elevated. Glycine, serine and threonine contribute to improve the growth performance of piglets and promote intestinal development and health [40-42]. However, the Glycine, serine, and threonine metabolism pathways declined in the social contact group, which might illustrate that social contact was a negative stress that influenced the body weight increase of the piglets.

\section{Conclusions}

In brief, our present work demonstrated that the early social contact could change the richness and diversity of gut microbiota during the suckling period, but not in the growing period. Meanwhile, early social contact notably causes taxonomic changes in the gut microbiome, altering the functional features of intestinal flora. At present, we speculate that the continuous social contact in the suckling period may be a stressor, but it is hard to determine definitively whether the continuous early social contact has a positive or negative effect on the gut intestinal microbial colonization of piglets. Further studies are required to elucidate the long-term indices for such factors as metabolism, immunity, and behavior, in order to evaluate the effect of early social contact on later pig growth and development.

\section{Abbreviations}

PCR: polymerase chain reaction; QIME: Quantitative insights into microbial ecology; PCoA: Principal coordinate analysis; PICRUSt: Phylogenetic investigation of communities by reconstruction of 
unobserved states; KEGG: Kyoto encyclopedia of genes and genomes; FDR: False discovery rate; COGs: Clusters of orthologous groups; SD: Standard deviation

\section{Declarations}

\section{Ethics approval and consent to participate}

All procedures were described in this study had been approved by the Northeast Agricultural University Animal Care and Use Committee (NEAU- [2011]-9).

\section{Consent for publication}

Not applicable

\section{Availability of data and materials}

The datasets supporting the conclusion of this article are included within the article.

\section{Competing interests}

The authors declare that they have no competing interests.

\section{Funding}

This study was supported by the Earmarked Fund for China Agriculture Research System (grant no. CARS-35-05B).

\section{Authors' contributions}

BYJ, HGL and JB designed the whole trial; RZL, BJ, XL, and JHL for animal feeding and care; LP and HDW charged for the sampling; YJB wrote the original draft; $\mathrm{HGL}, J B, H D W$ and RXL revised the manuscript. All authors read and approved the final manuscript.

\section{Acknowledgments}

The authors would like to thank Dr. Houjuan Xing, Dr. Peng Zhao, and Dr. Jo Hyen Soo for their help in the successful completion of this study.

\section{References}

1. Danneskioldsamsoe NB, Barros HDDFQ, Santos RD, Bicas JL, Cazarin CBB, Madsen L, et al. Interplay between food and gut microbiota in health and disease. Food Res Int. 2019; 115: 23-31.

2. Eisenstein M. The hunt for a healthy microbiome. Nature. 2020; 577(7792): S6-8. 
3. Kolde R, Franzosa EA, Rahnavard G, Hall AB, Vlamakis H, Stevens CR, et al. Host genetic variation and its microbiome interactions within the Human Microbiome Project. Genome Med. 2018; 10(1): 6. https://doi.org/10.1186/s13073-018-0515-8.

4. Kemis JH, Linke V, Barrett KL, Boehm FJ, and Rey FE. Genetic determinants of gut microbiota composition and bile acid profiles in mice. PLoS Genet. 2019; 15(8): e1008073. https://doi.org/ 10.1371/journal.pgen.1008073.

5. Li F, Hitch T, Chen Y, Creevey CJ, and Guan LL. Comparative metagenomic and metatranscriptomic analyses reveal the breed effect on the rumen microbiome and its associations with feed efficiency in beef cattle. Microbiome. 2019; 7(1): 6. https://doi.org/10.1186/s40168-019-0618-5.

6. Bian G, Ma S, Zhu Z, Su Y, Zoetendal EG, Mackie Rl, et al. Age, introduction of solid feed and weaning are more important determinants of gut bacterial succession in piglets than breed and nursing mother as revealed by a reciprocal cross-fostering model. Environ Microbiol. 2016; 18(5): 1566-77.

7. Pandit RJ, Hinsu AT, Patel N, Koringa PG, Jakhesara SJ, Thakkar JR, et al. Microbial diversity and community composition of caecal microbiota in commercial and indigenous Indian chickens determined using 16s rDNA amplicon sequencing. Microbiome. 2018; 6(1): 115. https://doi.org/10.1186/s40168-018-0501-9.

8. Coelho LP, Kultima JR, Costea PI, Fournier C, Pan Y, Czarneckimaulden G, et al. Similarity of the dog and human gut microbiomes in gene content and response to diet. Microbiome. 2018; 6(1): 72. https://doi.org/10.1186/s40168-018-0450-3.

9. Zhao J, Bai Y, Tao S, Zhang G, Wang J, Liu L, et al. Fiber-rich foods affected gut bacterial community and short-chain fatty acids production in pig model. J Funct Food. 2019; 57: 266-74.

10. Zeng B, Zhao J, Guo W, Zhang S, Hua Y, Tang J, et al. High-altitude living shapes the skin microbiome in humans and pigs. Front Microbiol. 2017; 8: 1929. https://doi.org/10.3389/fmicb.2017.01929.

11. He J, Guo H, Zheng W, Xue Y, Zhao R, and Yao W. Heat stress affects fecal microbial and metabolic alterations of primiparous sows during late gestation. J Anim Sci Biotechnol. 2019; 10(1): 84. https://doi.org/10.1186/s40104-019-0391-0.

12. Herd P, Palloni A, Rey FE, and Dowd JB. Social and population health science approaches to understand the human microbiome. Nat Hum Behav. 2018; 2(11): 808-15.

13. Guevarra RB, Lee JH, Lee SH, Seok M, Kim DW, Kang BN, et al. Piglet gut microbial shifts early in life: causes and effects. J Anim Sci Biotechnol. 2019; 10(1): 84. https://doi.org/10.1186/s40104-0180308-3.

14. Guevarra RB, Hong SH, Cho JH, Kim B, Shin J, Lee JH, et al. The dynamics of the piglet gut microbiome during the weaning transition in association with health and nutrition. J Anim Sci Biotechnol. 2018; 9(1): 54. https://doi.org/10.1186/s40104-018-0269-6.

15. Meng Q, Luo Z, Cao C, Sun S, and Shan A. Weaning alters intestinal gene expression involved in nutrient metabolism by shaping gut microbiota in pigs. Front Microbiol. 2020; 11: 694. https://doi.org/10.3389/fmicb.2020.00694. 
16. Hameister T, Puppe B, Tuchscherer M, and Kanitz E. Effects of weaning age on behavioural and physiological responses of domestic piglets - A review. Berliner Und Münchener Tierärztl Wochenschr. 2010; 123(1-2): 11-9.

17. Campbell JM, Crenshaw JD, and Polo J. The biological stress of early weaned piglets. J Anim Sci Biotechnol. 2013; 4(1): 19. https://doi.org/10.1186/2049-1891-4-19.

18. Pohl CS, Medland JE, Mackey E, Edwards LL, Bagley KD, DeWilde MP, et al. Early weaning stress induces chronic functional diarrhea, intestinal barrier defects, and increased mast cell activity in a porcine model of early life adversity. Neurogastroenterol Motil. 2017; 29(11): e13118. https://doi.org/10.1111/nmo.13118.

19. Wijtten PJA, Der Meulen JV, and Verstegen MWA. Intestinal barrier function and absorption in pigs after weaning: a review. Br J Nutr. 2011; 105(7): 967-81.

20. Li Y, Guo Y, Wen Z, Jiang X, Ma X, and Han X. Weaning stress perturbs gut microbiome and its metabolic profile in piglets. Sci Rep. 2018; 8(1): 18068. https://doi.org/10.1038/s41598-018-336498.

21. Ke SL, Fang SM, He MZ, Huang XC, Yang H, Yang B, et al. Age-based dynamic changes of phylogenetic composition and interaction networks of health pig gut microbiome feeding in a uniformed condition. BMC Vet Res. 2019; 15: 172. https://doi.org/10.1186/s12917-019-1918-5.

22. Gaillard C, Meagher RK, Von Keyserlingk MAG, and Weary DM. Social housing improves dairy calves' performance in two cognitive tests. PLoS One. 2014; 9(2): e90205. https://doi.org/ 10.1371/journal.pone.0090205.

23. Kambali MY, Anshu K, Kutty BM, Muddashetty RS, and Laxmi TR. Effect of early maternal separation stress on attention, spatial learning and social interaction behaviour. Exp Brain Res. 2019; 237(8): 1993-2010.

24. Marshall HH, Vitikainen EIK, Mwanguhya F, Businge R, Kyabulima S, Hares MC, et al. Lifetime fitness consequences of early-life ecological hardship in a wild mammal population. Ecol Evol. 2017; 7(6): 1712-24.

25. Su Y, Zhang X, Xin H, Li S, Li J, Zhang R, et al. Effects of prior cold stimulation on inflammatory and immune regulation in ileum of cold-stressed broilers. Poult Sci. 2018; 97(12): 4228-37.

26. Salazar LC, Ko HL, Yang CH, Llonch L, Manteca X, Camerlink I, et al. Early socialisation as a strategy to increase piglets' social skills in intensive farming conditions. Appl Anim Behav Sci. 2018; 206: 2531.

27. Mulder I, Schmidt B, Stokes CR, Lewis M, Bailey M, Aminov RI, et al. Environmentally-acquired bacteria influence microbial diversity and natural innate immune responses at gut surfaces. BMC Biol. 2009; 7(1): 79. https://doi.org/10.1186/1741-7007-7-79.

28. Wikberg EC, Christie D, Sicotte P, and Ting N. Interactions between social groups of colobus monkeys (Colobus vellerosus) explain similarities in their gut microbiomes. Anim Behav. 2020; 163: 17-31.

29. Garcia MS, Ko HL, Sorrento AR, Obiols PL, Hernandez JFP, and Orue SMM. PSVI-35 The combined effects of early-socialization of piglets and neonatal enriched environment on intestinal gene 
expression and fecal community structure. J Anim Sci. 2019; 97: 204.

https://doi.org/10.1093/jas/skz258.420.

30. Li N, Huang S, Jiang L, Dai Z, Li T, Han D, et al. Characterization of the early life microbiota development and predominant lactobacillus species at distinct gut segments of low- and normalbirth-weight piglets. Front Microbiol. 2019; 10: 797. https://doi.org/ 10.3389/fmicb.2019.00797.

31. Han GG, Lee J, Jin G, Park J, Choi YH, Chae BJ, et al. Evaluating the association between body weight and the intestinal microbiota of weaned piglets via 16S rRNA sequencing. Appl Microbiol Biotechnol. 2017; 101(14): 5903-11.

32. Bervoets L, Van Hoorenbeeck K, Kortleven I, Van Noten C, Hens N, Vael C, et al. Differences in gut microbiota composition between obese and lean children: a cross-sectional study. Gut Pathogens. 2013; 5(1): 10. https://doi.org/10.1186/1757-4749-5-10.

33. Frese SA, Parker K, Calvert CC, and Mills DA. Diet shapes the gut microbiome of pigs during nursing and weaning. Microbiome. 2015; 3(1): 28-28.

34. Cai H, Thompson R, Budinich M, Broadbent JR, and Steele JL. Genome sequence and comparative genome analysis of Lactobacillus casei: insights into their niche-associated evolution. Genome Biol Evol. 2009; 1(1): 239-57.

35. Ivarsson E, Roos S, Liu H, and Lindberg JE. Fermentable non-starch polysaccharides increases the abundance of Bacteroides-Prevotella-Porphyromonas in ileal microbial community of growing pigs. Animal. 2014; 8(11): 1777-87.

36. Wu W, Sun M, Chen F, Cao AT, Liu H, Zhao Y, et al. Microbiota metabolite short-chain fatty acid acetate promotes intestinal IgA response to microbiota which is mediated by GPR43. Mucosal Immunol. 2017; 10(4): 946-56.

37. Dalile B, Van Oudenhove L, Vervliet B, and Verbeke K. The role of short-chain fatty acids in microbiota-gut-brain communication. Nat Rev Gastroenterol Hepatol. 2019; 16(8): 461-78.

38. Downes J, Dewhirst FE, Tanner ACR, and Wade WG. Description of Alloprevotella rava gen. nov., sp. nov., isolated from the human oral cavity, and reclassification of Prevotella tannerae Moore et al. 1994 as Alloprevotella tannerae gen. nov., comb. nov. Int J Syst Evol Microbiol. 2013; 63(Pt 4): 12148.

39. Lynch JB and Hsiao EY. Microbiomes as sources of emergent host phenotypes. Science. 2019; 365(6460): 1405-9.

40. Wang W, Dai Z, Wu Z, Lin G, Jia S, Hu S, et al. Glycine is a nutritionally essential amino acid for maximal growth of milk-fed young pigs. Amino Acids. 2014; 46(8): 2037-45.

41. Xu X, Wang X, Wu H, Zhu H, Liu C, Hou Y, et al. Glycine relieves intestinal injury by maintaining mTOR signaling and suppressing AMPK, TLR4, and NOD signaling in weaned piglets after lipopolysaccharide challenge. Int J Mol Sci. 2018; 19(7): 1980. https://doi.org/ 10.3390/ijms19071980.

42. Zhou X, Zhang Y, Wu X, Wan D, and Yin Y. Effects of Dietary Serine Supplementation on Intestinal Integrity, Inflammation and Oxidative Status in Early-Weaned Piglets. Cell Physiol Biochem. 2018; 
48(3): 993-1002.

Figures
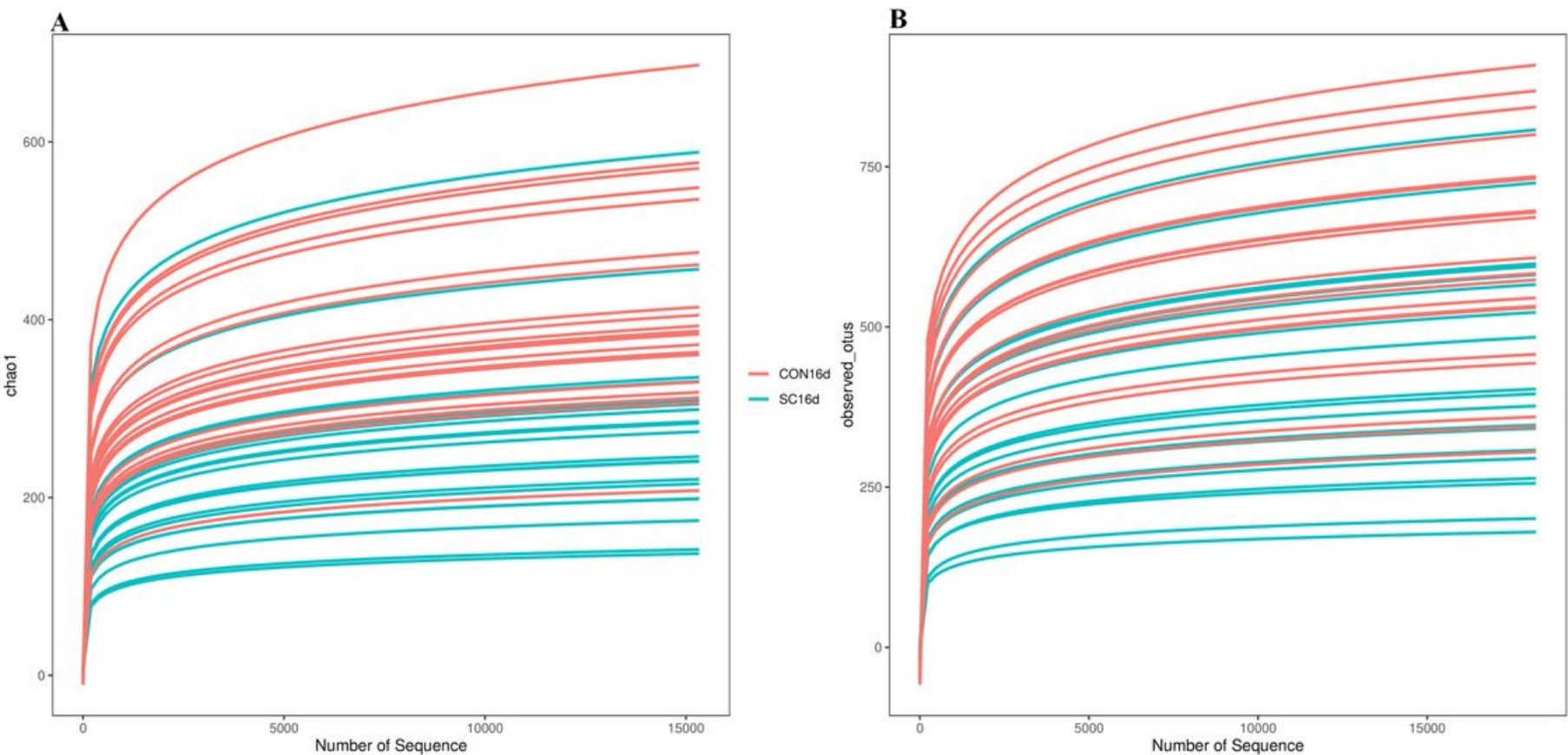

- CON35

- sc35d
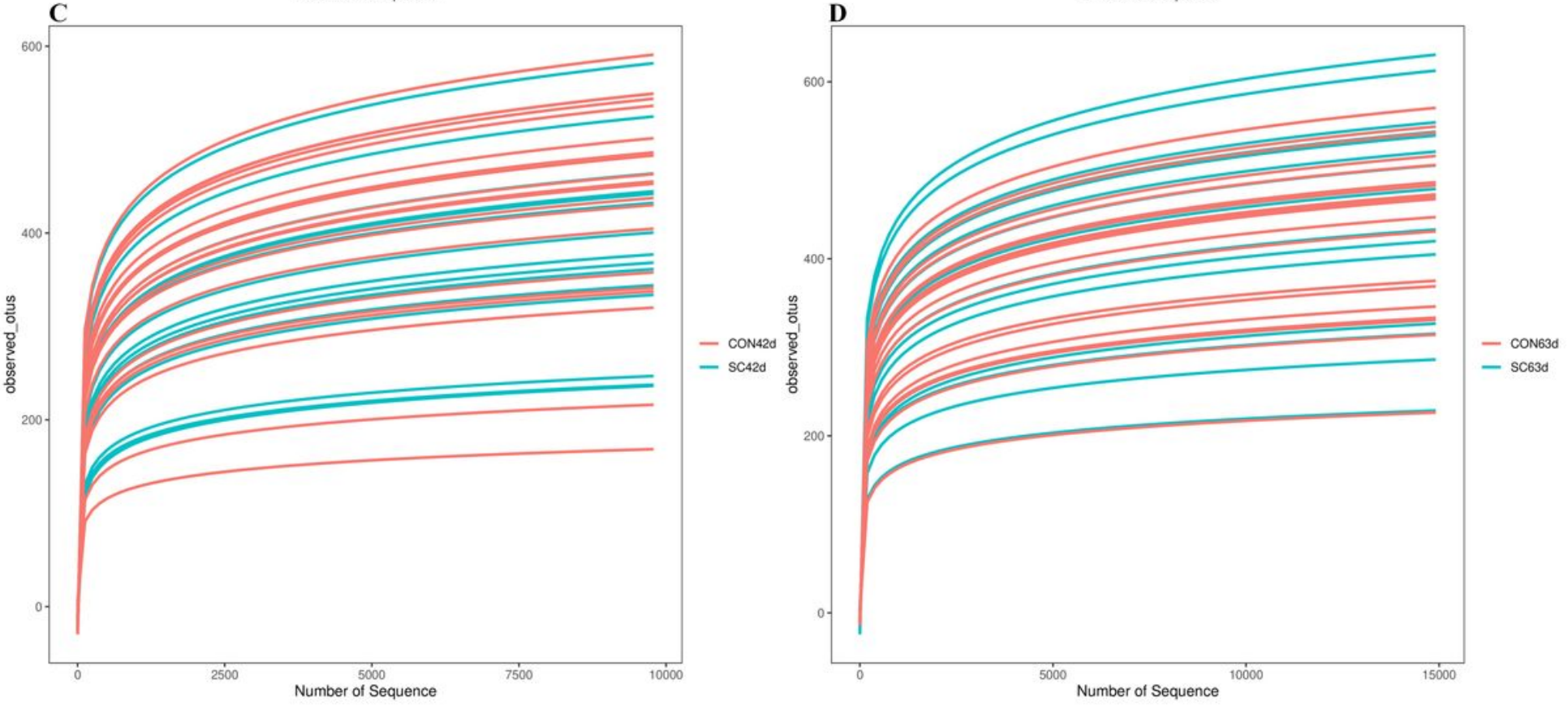

Figure 1

Rarefaction curves of observed species indictor of piglets. (A) 16 days, (B) 35 days, (C) 42 days, and (D) 63 days. CON control; SC, social contact. 
A PCoA plot ( $P=0.001)$
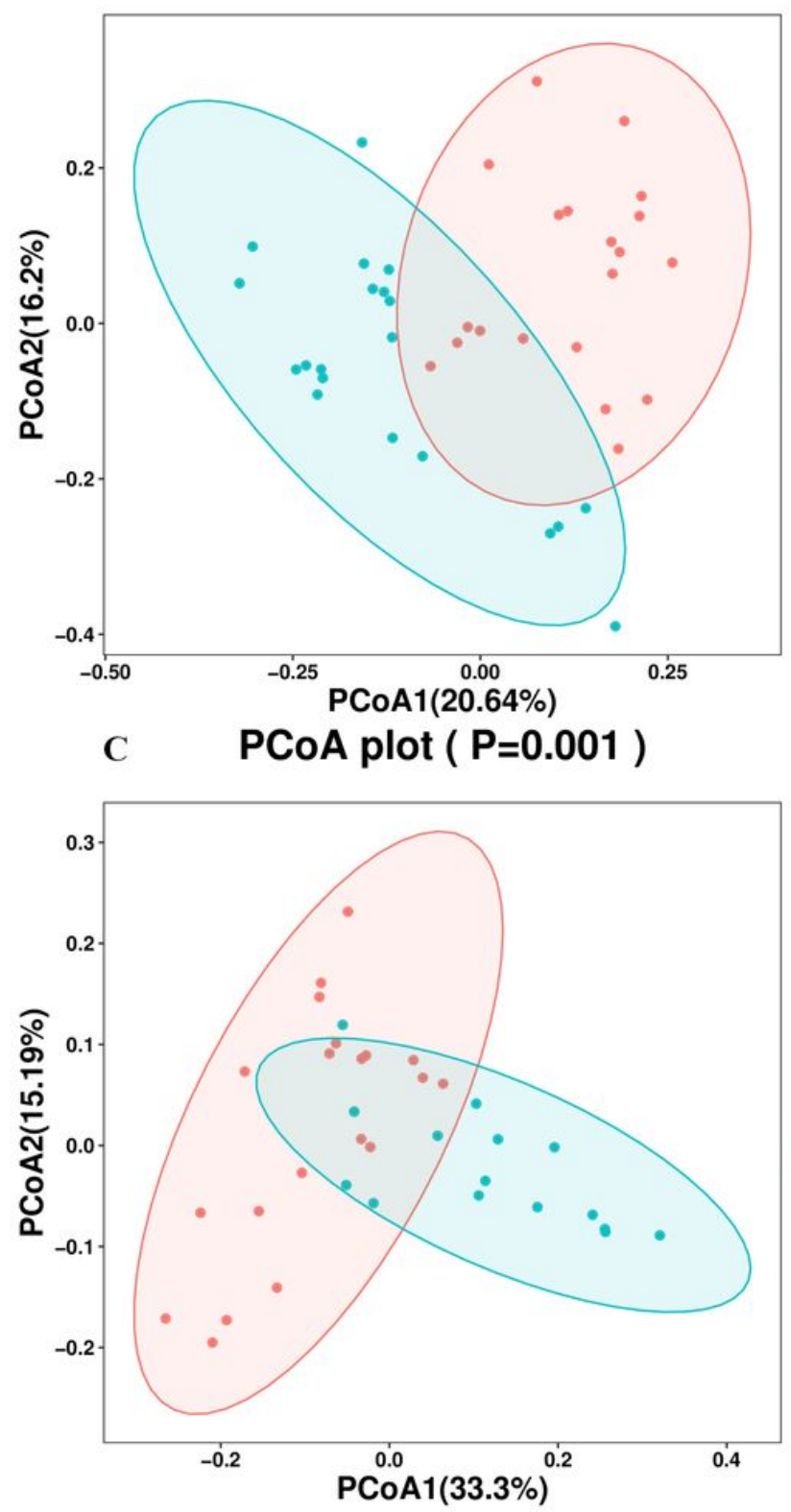

B PCoA plot $(\mathrm{P}=\mathbf{0 . 0 0 1 )}$
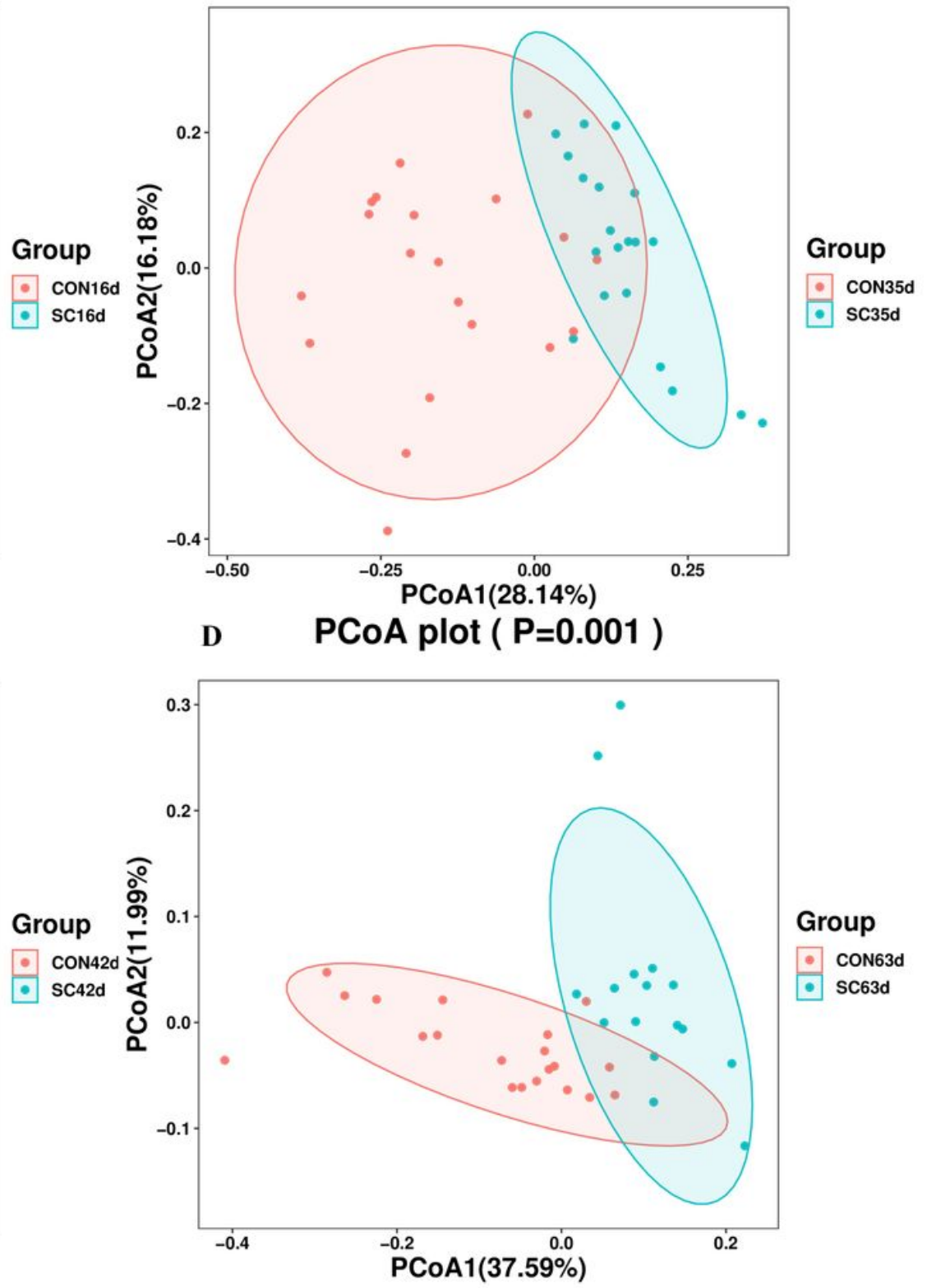

Figure 2

Principal coordinate analysis (PCoA) in fecal samples based on weighted UniFrac distances. (A) 16 days, (B) 35 days, (C) 42 days, and (D) 63 days. CON, control; SC, social contact. 

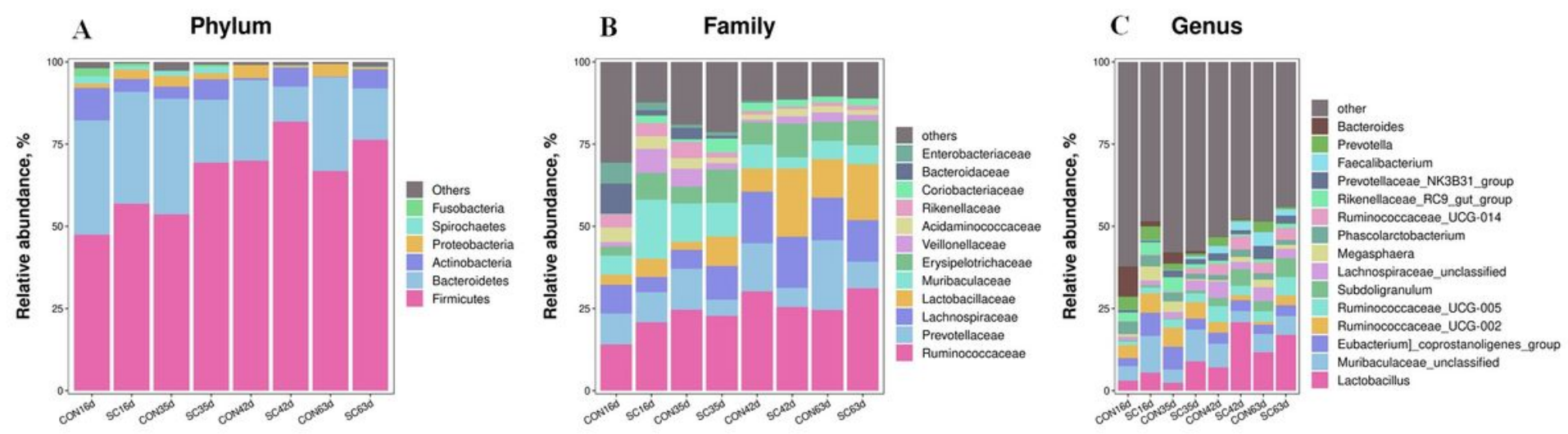

Figure 3

Fecal microbiota composition of CON and SC piglets. Abundant phyla (A), Family(B), and genus(C) in the fecal microbiota of CON and SC piglets. CON, control; SC, social contact.

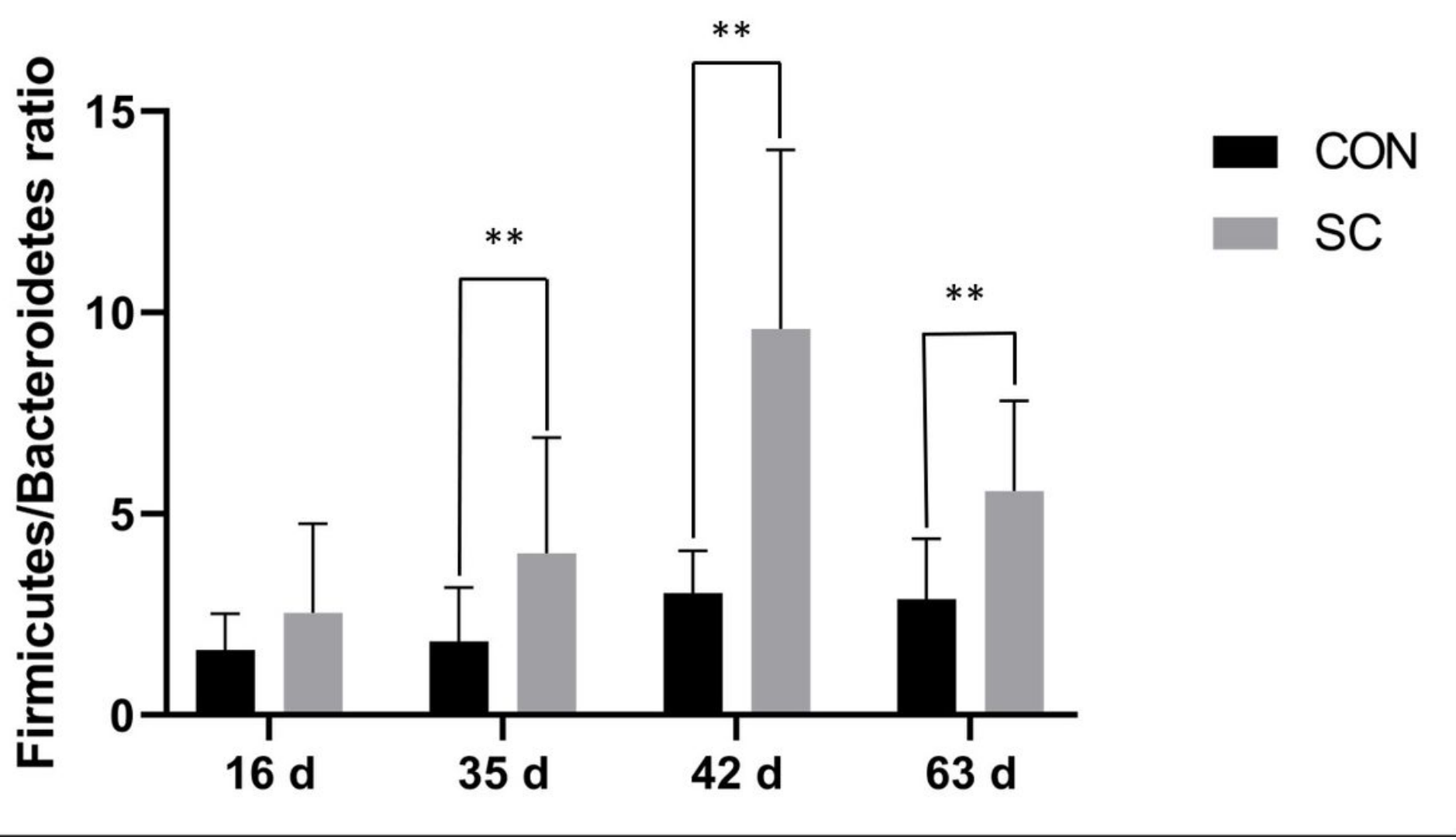

Figure 4

The effect of social contact on Firmicutes-to-Bacteroidetes ratio for piglets. * represents statistical significance $(P<0.05)$, ** represents statistical significance $(P<0.01)$ between CON and SC groups. CON, control; SC, social contact. 
A

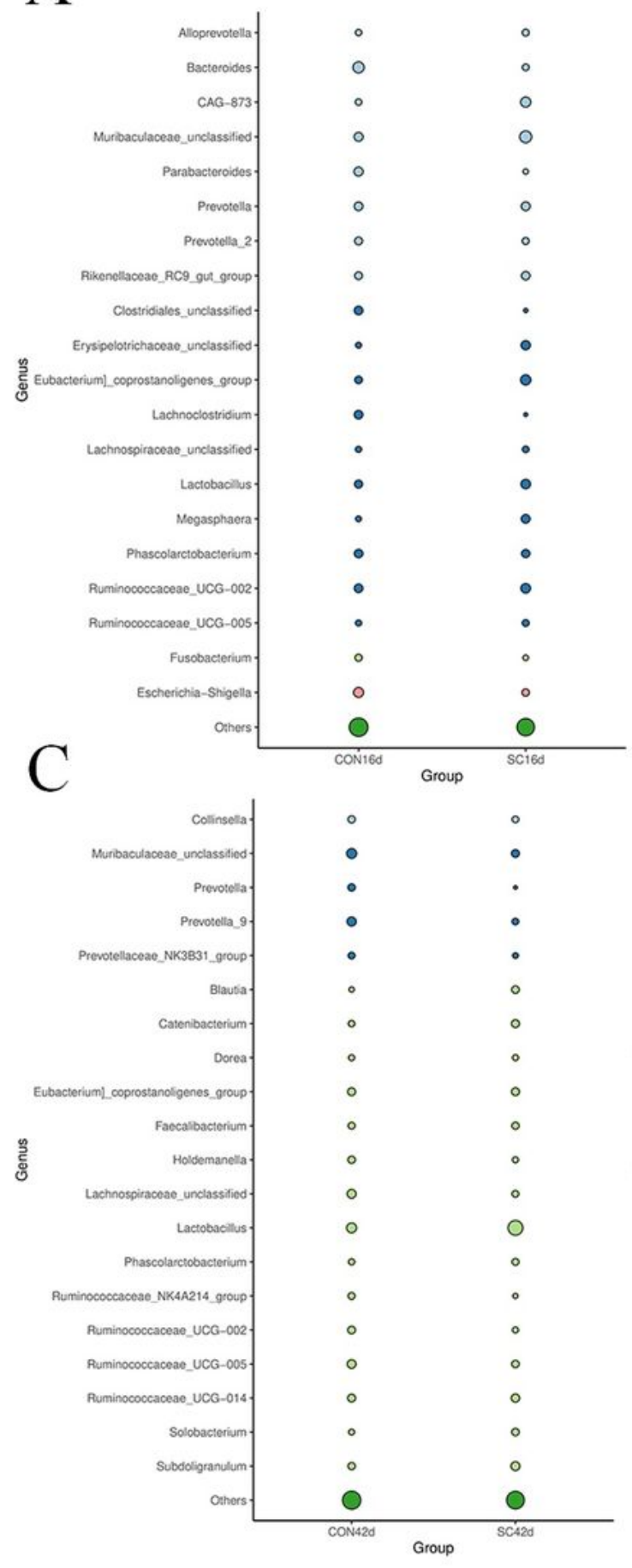

$\mathrm{B}$

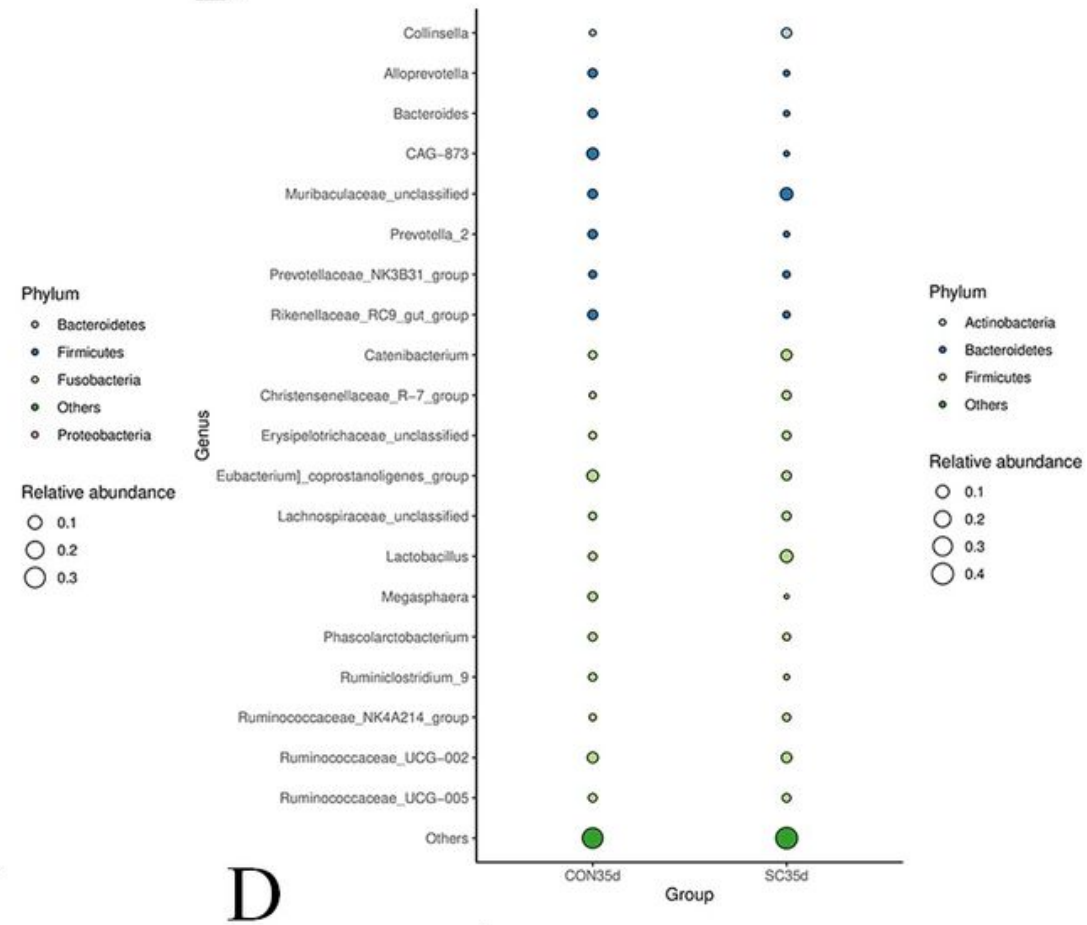

Relative abundance

0.1

$\begin{array}{ll}0 & 0.1 \\ O & 0.2\end{array}$

0.3

Phylum

$\mathrm{D}$

- Bacteroidetes

- Firmicutos

- Others

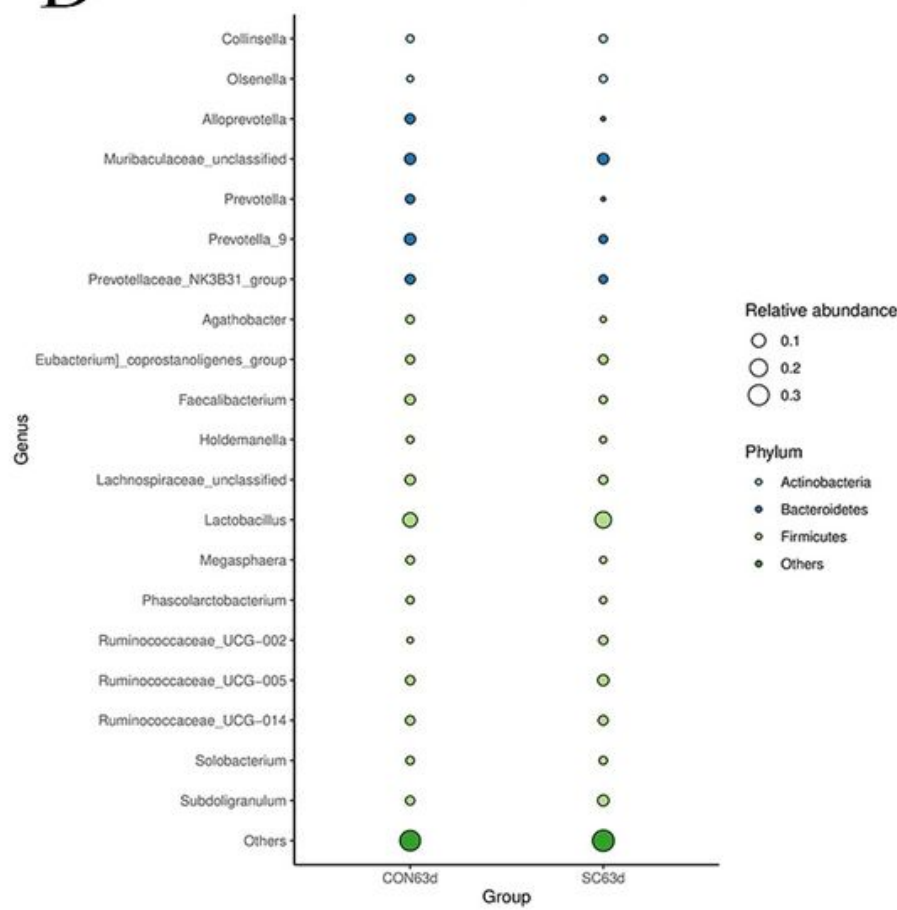

Figure 5

The bubble blot on genus level in fecal microbiota of piglets. (A) 16 days, (B) 35 days, (C) 42 days, and (D) 63 days. CON, control; SC, social contact. 
A

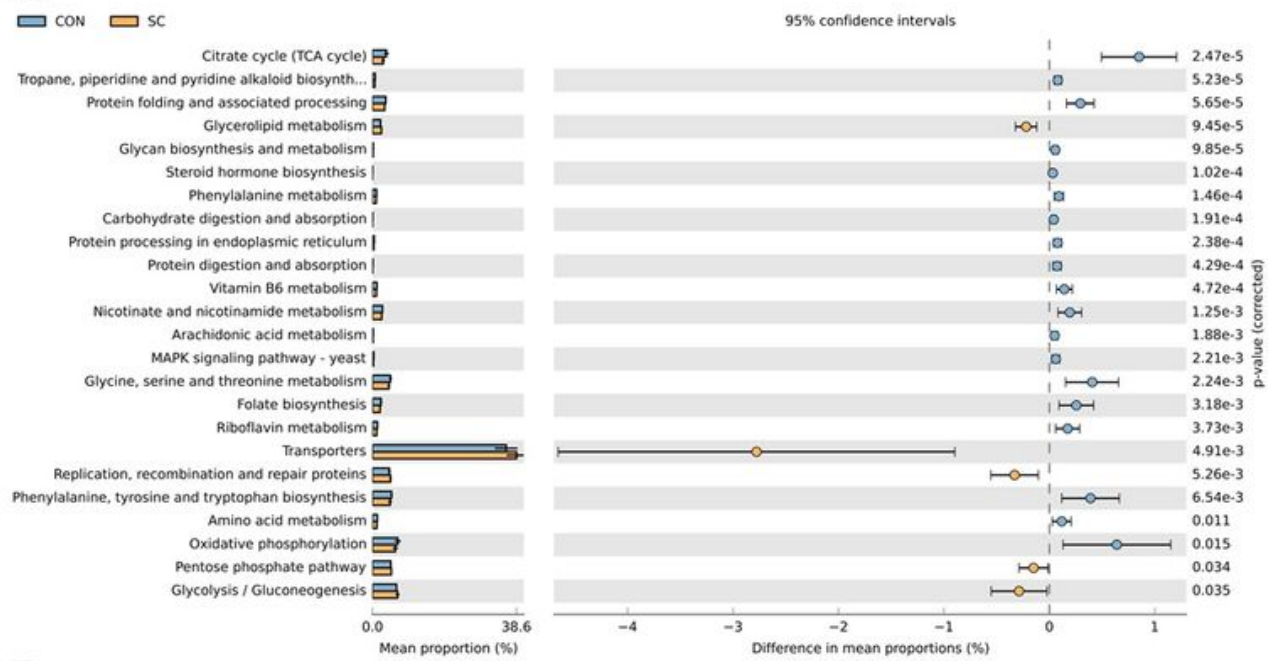

$\mathrm{B}$

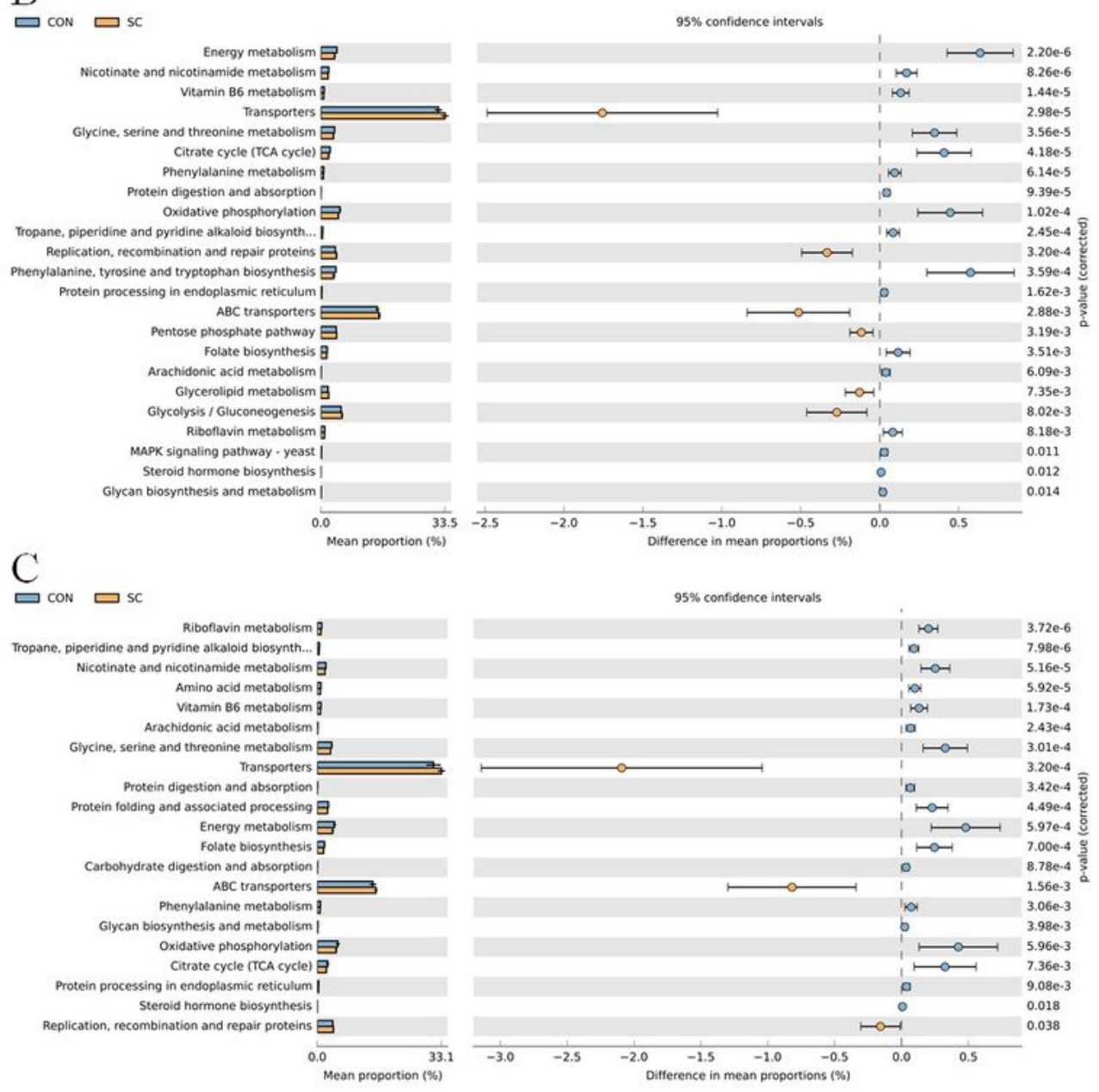

\section{Figure 6}

Predicted microbial function the feces of CON and SC groups. (A) 35 days, (B) 42 days, and (C) 63 days. The third level KEGG pathways were shown in the extend error bas. Blue and yellow represented SC group and CON group, respectively. CON, control; SC, social contact. 


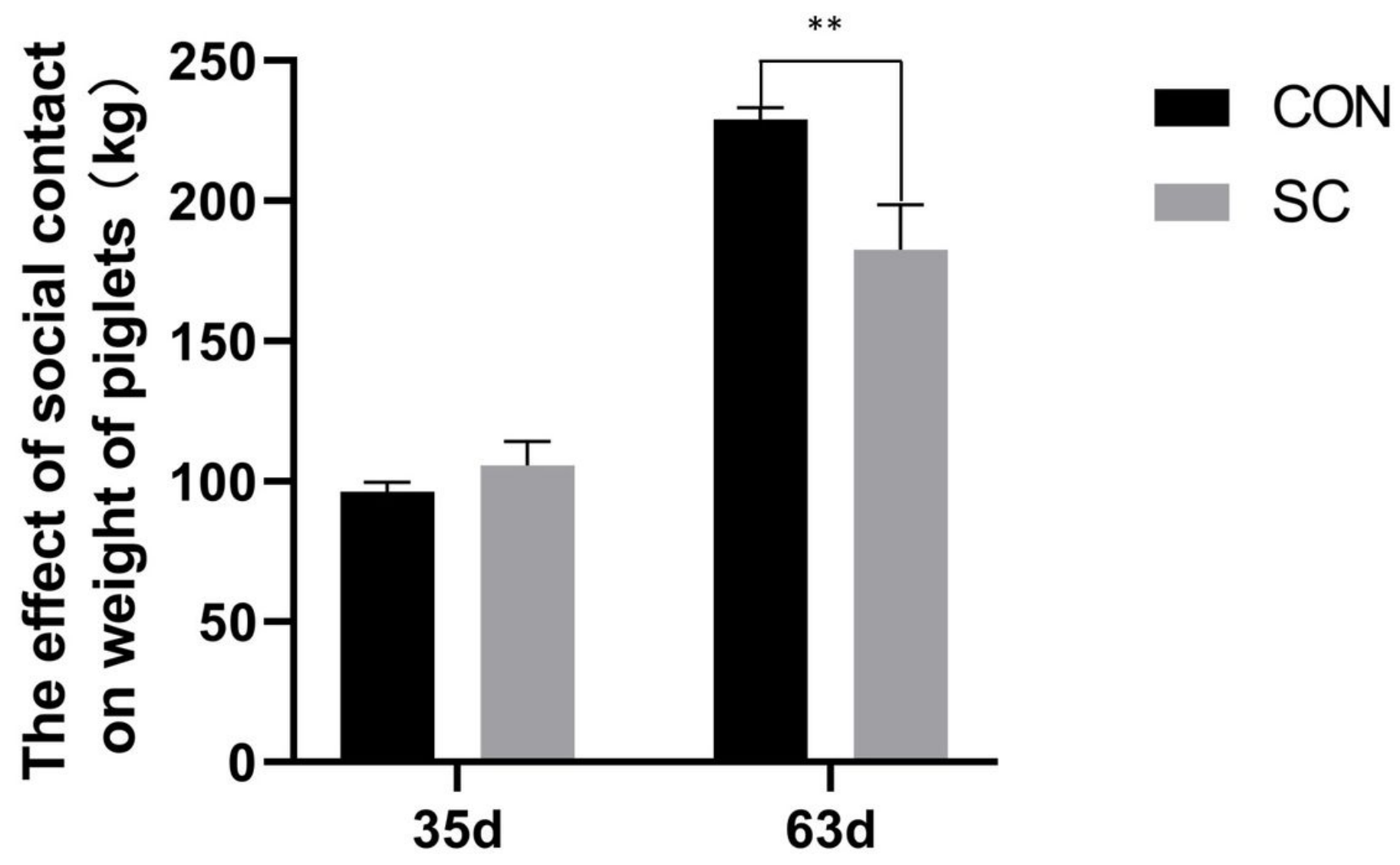

Figure 7

The effect of social contact on the weight of piglets. * represents statistical significance $(P<0.05)$, ** represents statistical significance $(P<0.01)$ between CON and SC groups. CON, control; SC, social contact.

\section{Supplementary Files}

This is a list of supplementary files associated with this preprint. Click to download.

- Aditionalfile1.xIsx

- Aditionalfile2.xIsx

- Additionalfile3.xIsx

- Additionalfile4.xlsx

- Additionalfile5.xlsx 